\title{
The influence of competences in business higher education: a student's approach
}

\author{
Borraz-Mora, Javier; Hernández-Ortega, Blanca and Melguizo-Garde, Marta* \\ ${ }^{a}$ Faculty of Business and Economics, Universidad de Zaragoza, Spain.
}

\begin{abstract}
Nowadays, competences have an important role in higher education. Their development may have an effect on student's satisfaction with his/her studies. The aim of this research is to test the relationship between competences developed during the study of a university business degree and the student's satisfaction with this degree. Moreover, we test other outcomes derived from satisfaction, such as the student's word of mouth and his/her confirmation of the university degree that he/she chose. We design an online survey for students of the Faculty of Economics and Business Administration in a Spanish University. We collect 161 effective questionnaires and analyse them using structural equation modelling, specifically partial least square (PLS). Results demonstrate that competences have a strong effect on student's satisfaction, leading to positive word of mouth and confirmation of student's past behaviour. This implies that specifying and working properly the competences of a degree becomes a priority objective for university institutions.
\end{abstract}

Keywords: Competences; Satisfaction; Word of mouth; Behavioural confirmation.

*Authors are grateful to University of Zaragoza for funding this research (PIPOUZ 16-216). 


\section{Introduction}

In recent years, one of the major changes that has occurred in the context of higher education has been to focus on the acquisition of competences by students. The project "Tuning Educational Structures in Europe" highlights the concept of competence as the ability of a person to perform certain issues related to knowledge, applications or attitudes. Competences are categorized into subject-specific and general-academic. While subjectspecific competences depend on the area or subject, general-academic competences are multidisciplinary, so they can be considered as transversal competences (Parvu et al., 2014). Therefore, general competences allow the comparison between students with different educational profiles, and can be seen as a minimum necessary for the adequate incorporation of postgraduates into the labour market.

General-academic competences are usually classified into three groups: instrumental, interpersonal and systemic. Instrumental competences are characterized by cognitive, methodological, technological and linguistic abilities. These include aspects such as the individual's ability to analyse and synthesize, to learn foreign languages, or to make decisions. Interpersonal competences refer to individual abilities like social skills (social interaction, ethical commitment and co-operation). Finally, systemic competences are focused on the student's abilities concerning whole systems, such as combination of understanding, sensibility and knowledge.

Competences have attracted the attention of researchers due to their importance in higher education. Several works have tried to determine what tools promote the individuals' acquisition of competences and have addressed the analysis of competences and skills according to the area of study (Sanahuja et al., 2016; Weinstein, 2016). Moreover, other authors have tested the evaluation that recent postgraduates carry out about the competences acquired to develop the career that they want to perform (Azevedo et al., 2012). The relationship between the development of competences and the student's satisfaction with his/her education demands higher attention, especially whether we take into account that the individual's satisfaction diminishes the dropout rate (e.g., Duque, 2014; Gairín et al., 2014). In this context, a relevant topic that deserves more attention would be the influence of competences on the overall individual's satisfaction with his/her studies (Azevedo et al., 2008).

The aim of the present research is to establish the relationship between competences developed during the study of a business university degree and the student's satisfaction with this degree. Moreover, this research addresses other outcomes derived from satisfaction that have been hardly tested, such as the student's recommendations (i.e., word of mouth) and his/her confirmation of the university degree that he/she chose. Nowadays, the analysis of these relationships is essential because the total implementation of the 
degrees is ending and universities should know the student's evaluations. Our study allows us to draw conclusions about the importance of the competences developed, in order to improve the degrees.

This research is structured as follows: Section 2 formulates the conceptual model and proposes hypotheses. Section 3 explains the methodology applied and section 4 exposes findings. Finally, conclusions and implications are described.

\section{Conceptual model and hypotheses}

Student's satisfaction depends on the academic achievements that he/she has obtained, not only in terms of scores but also related to his/her learning performance (Wilkins et al., 2016). Precisely, the concepts of learning, ability, capacity and skill are those that support the idea of competences. Recent works have shown that competences developed through specific subjects (e.g., related to marketing) have a significant influence on student's satisfaction with these subjects (De Juan-Vigaray and González-Gascón, 2013; Orús et al., 2016). Therefore, our first hypotheses highlight this relationship for university degrees:

H1. The development of competences in a university degree positively influences the student's satisfaction with this degree.

Several studies have demonstrated that recommendations (e.g., word of mouth) and the intention to confirm a particular behaviour are outcomes of the individual's satisfaction (e.g., Vila-López and Küster-Boluda, 2016). In the educational field, satisfaction is considered a strong determinant of loyalty, the latter being measured as the conjunction of the student's recommendations and intentions to repeat his/her behaviour (Brown and Mazzarol, 2009; De Juan-Vigaray and González-Gascón, 2013). Following these ideas, we hypothesize the following relationships:

H2. Student's satisfaction with the degree positively influences the recommendations that he/she makes.

H3. Student`s satisfaction with the degree positively influences the confirmation of his/her choice.

Figure 1 shows the conceptual model proposed. 


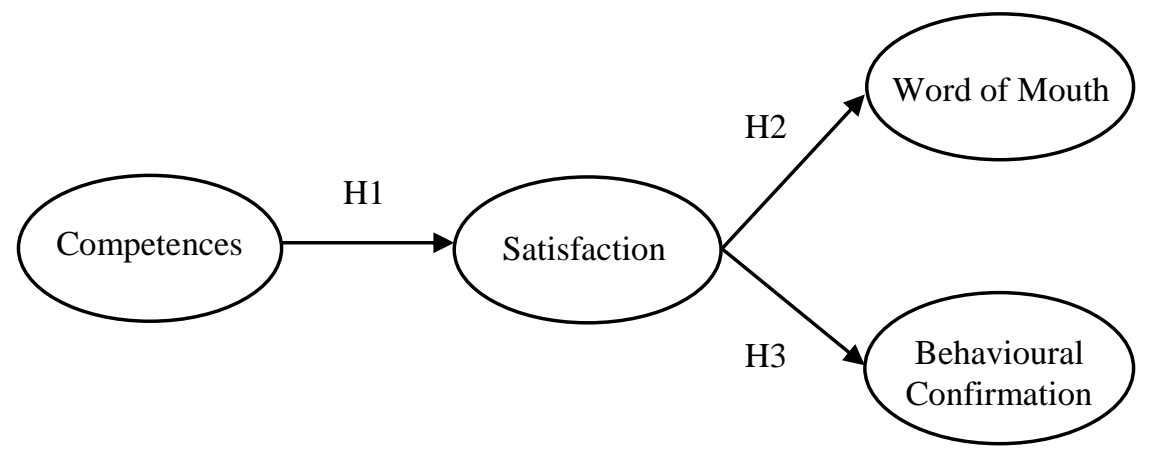

Figure 1. Conceptual model. Source: Own elaboration.

\section{Methodology and analysis of model}

We design an online survey to collect data, using Google Drive platform. The targeted respondents are students of any academic degree and course attached to the Faculty of Economics and Business Administration of a Spanish University (University of Zaragoza). 165 students responded to the questionnaire but 4 were eliminated because of missing data, so 161 effective questionnaires were used for the analysis (61.39\% female).

Table 1 shows the items used for each variable of the model. We use the list of 26 general competences (divided into instrumental, interpersonal and systemic competences) established by the University of Zaragoza in order to measure the competences factor. Table 1 also presents the items loadings, composite reliability (CR) and construct's average variance extracted (AVE). The scales meet the requirements of these analyses in order to ensure reliability and convergent validity (Hair et al., 2010). Finally, we ensure discriminant validity checking that the square root of AVE values are larger than their correlation values (Fornell and Larcker, 1981). 
Table 1. Items, reliability and convergent validity.

\begin{tabular}{|c|c|c|c|}
\hline Variable / Item & Loadings & $\mathbf{C R}$ & AVE \\
\hline COMPETENCES & & 0.90 & 0.75 \\
\hline COM1: Instrumental (8 items) & 0.888 & & \\
\hline COM2: Interpersonal (9 items) & 0.871 & & \\
\hline COM3: Systemic (9 items) & 0.835 & & \\
\hline SATISFACTION & & 0.95 & 0.87 \\
\hline SAT1: In general, I am satisfied with my degree & 0.932 & & \\
\hline SAT2: My degree is meeting my expectations & 0.933 & & \\
\hline SAT3: Studying my degree is satisfactory & 0.925 & & \\
\hline WORD OF MOUTH & & 0.95 & 0.85 \\
\hline $\begin{array}{l}\text { WOM1: I will speak positively of my degree to my friends and } \\
\text { acquaintances }\end{array}$ & 0.917 & & \\
\hline WOM2: I will encourage other people to study my degree & 0.925 & & \\
\hline $\begin{array}{l}\text { WOM3: I will recommend to study my degree to anyone who } \\
\text { asks me }\end{array}$ & 0.931 & & \\
\hline BEHAVIOURAL CONFIRMATION & & 0.95 & 0.87 \\
\hline $\begin{array}{c}\text { BC1: If nowadays I had to decide which degree to study, I } \\
\text { would choose the same }\end{array}$ & 0.966 & & \\
\hline $\begin{array}{l}\text { BC2: Without a doubt, I would choose to study the degree that I } \\
\text { am currently studying }\end{array}$ & 0.957 & & \\
\hline $\begin{array}{l}\text { BC3: If I could go back to the past, I would not choose the } \\
\text { degree I am currently studying* }\end{array}$ & 0.865 & & \\
\hline
\end{tabular}

*Reverse coded. Source: Own elaboration. 


\section{Results}

Structural equation modelling was applied, specifically partial least square (PLS) with SmartPLS 2.0 M3 software. This technique is increasingly used as it does not assume any type of data distribution and it provides good estimates even when the sample size is relatively small (e.g., Orús et al., 2016).

Figure 2 shows the structural model results (path coefficients, its significance and $\mathrm{R}^{2}$ for dependent variables). The development of competences throughout the degree has a positive effect on the student's satisfaction with their degree $(\beta=0.445 ; \mathrm{t}=7.380)$. Therefore, $\mathrm{H} 1$ is supported. Moreover, student's satisfaction positively affects both word of mouth $(\beta=0.831 ; \mathrm{t}=26.715)$ and behavioural confirmation $(\beta=0.753 ; \mathrm{t}=20.373)$, so H2 and $\mathrm{H} 3$ are confirmed. Our model explains nearly $20 \%$ of the variance $\left(\mathrm{R}^{2}\right)$ of satisfaction, $69.1 \%$ of the variance of word of mouth, and $56.7 \%$ of the variance of behavioural confirmation.

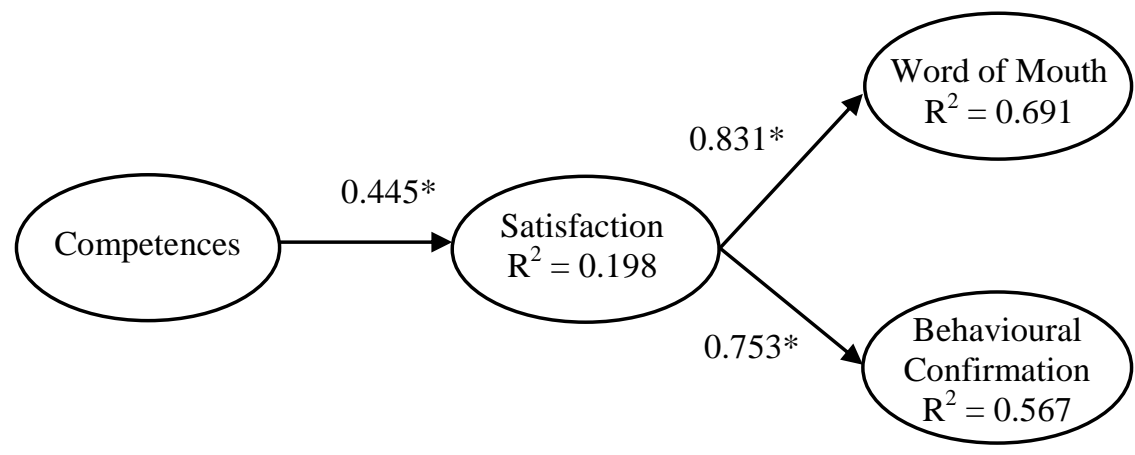

Figure 2.Structural model results. $* p<0.001$. Source: Own elaboration.

Finally, we calculate the indirect effects of competences on the two final dependent variables of the model. The total effect of competences on word of mouth and behavioural confirmation are $\beta=0.370$ and $\beta=0.335$, respectively. We use both Sobel (1982) test and Preacher and Hayes (2008) macro for SPSS in order to confirm the mediation effect of satisfaction on the relationship between competences and both word of mouth and behavioural confirmation. Results demonstrate this mediation effect, providing support for indirect effects. Specifically, we find an indirect-only mediation for competences-word of mouth relationship and a competitive mediation for competences-behavioural confirmation relationship (Zhao et al., 2010). 


\section{Conclusions and implications}

The main objective of this study is to test whether the development of general competences in higher education degrees affects student's satisfaction. Previous studies analysed the importance of competences, for example, to increase the individual's adaptation to the labor market (Azevedo et al., 2012), or to improve the student's satisfaction with specific subjects (De Juan-Vigaray and Gonzalez-Gascón, 2013; Orús et al., 2016). Our study contributes to this literature analysing this relationship in the context of complete degrees. Results confirm that competences that are developed during the study of a business degree contribute to increase the level of student's satisfaction with that degree. We also aimed to demonstrate the relationship between satisfaction and other outcomes. Previous studies have pointed the importance of recommendations (word of mouth) and the intention to repeat past behaviours as proxies to understand the student's loyalty (e.g., Brown and Mazzarol, 2009). Our findings verify the influence of student's satisfaction on word of mouth and behavioural confirmation.

University institutions are immersed in continuous changes and adaptions to their environment, the European Superior Education Space being one of the most important in the last years. This adaptation has involved the inclusion of competences in degrees, whose development has become a priority for institutions. The development of competences in the university enables students to acquire important skills and abilities, which improves not only the student's academic performance, but also his/her opportunity to get a better job in the future (Kong and Yang, 2014). In this way, if students perceive that they have acquired general competences, they will be satisfied with the degree, will increase his/her recommendations to colleagues and friends, and will feel that his/her election was correct, leading to a greater loyalty (Brown and Mazzarol, 2009; Gairín et al., 2014). All these facts will decrease the dropout rate and improve the recruitment of new students, even more in the age of social media when information is disseminated quickly (James and Casidy, 2016). Therefore, institutions have to use all necessary means to develop general competences related to the whole degree and not only to a specific subject. 


\section{References}

Azevedo, A., Apfelthaler, G., \& Hurst, D. (2012). Competency development in business graduates: An industry-driven approach for examining the alignment of undergraduate business education with industry requirements. The International Journal of Management Education, 10(1), 12-28.

Azevedo, A., Gomezelj, D., Andrews, J., Higson, H., \& Caballero, A. (2008, September). The impact of learning outcomes in business education: assessing value, relevance and graduate ability in a multi-country study of employers and business graduates. In IMHE general conference of the OECD, Paris, September 2008.

Brown, R. M., \& Mazzarol, T. W. (2009). The importance of institutional image to student satisfaction and loyalty within higher education. Higher Education, 58(1), 81-95.

De Juan-Vigaray, M., \& Gonzalez Gascón, E. (2013). Estudiantes de marketing: nivel de satisfacción y desarrollo de competencias como factores clave para las instituciones de educación superior. En XXV Congreso Nacional de Marketing, organizadas por AEMARK, Barcelona, 18-20 Septiembre, Editorial ESIC.

Duque, L. C. (2014). A framework for analysing higher education performance: students' satisfaction, perceived learning outcomes, and dropout intentions. Total Quality Management \& Business Excellence, 25(1-2), 1-21.

Fornell, C., \& Larcker, D. F. (1981). Evaluating structural equation models with unobservable variables and measurement error. Journal of Marketing Research, 39-50.

Gairín, J., Triado, X. M., Feixas, M., Figuera, P., Aparicio-Chueca, P., \& Torrado, M. (2014). Student dropout rates in Catalan universities: profile and motives for disengagement. Quality in Higher Education, 20(2), 165-182.

Hair, J. F., Black, W. C., Babin, B. J., \& Anderson, R. E. (2010). Multivariate Data Analysis. Englewood, Cliffs, NJ: Prentice Hall.

James, L. T., \& Casidy, R. (2016). Authentic assessment in business education: its effects on student satisfaction and promoting behaviour. Studies in Higher Education, 1-15.

Kong, H., \& Yan, Q. (2014). The relationship between learning satisfaction and career competencies. International Journal of Hospitality Management, 41, 133-139.

Orús, C., Barlés, M. J., Belanche, D., Casaló, L., Fraj, E., \& Gurrea, R. (2016). The effects of learner-generated videos for YouTube on learning outcomes and satisfaction. Computers \& Education, 95, 254-269.

Parvu, I., Ipate, D. M., \& Mitran, P. C. (2014). Identification of employability skills starting point for the curriculum design process. Economics, Management, and Financial Markets, 9(1), 237-246.

Preacher, K. J., \& Hayes, A.F. (2008). Asymptotic and resampling strategies for assessing and comparing indirect effects in multiple mediator models. Behavior research methods, 40(3), 879-891.

Sanahuja, G., Ribes, G., \& Moya, I. (2016). Business internships and new technologies: a scenario for growth and innovation. 2nd International Conference on Higher Education Advances, HEAd'16. DOI: http://dx.doi.org/10.4995/HEAd16.2016.2596. 
Sobel, M.E. (1982). Asymptotic confidence intervals for indirect effects in structural equation models. Sociological Methodology, 13, 290-312.

Vila-Lopez, N., \& Küster-Boluda, I. (2016). Excellent products or servitisation? Analysing retailers' preference before and after a loyalty programme. Total Quality Management \& Business Excellence, 1-15.

Weinstein, K. (2016). Visualizing the critique: Strengthening quantitative reasoning skills through design. 2nd International Conference on Higher Education Advances, HEAd'16. DOI: http://dx.doi.org/10.4995/HEAd16.2016.2546.

Wilkins, S., Butt, M. M., Kratochvil, D., \& Balakrishnan, M. S. (2016). The effects of social identification and organizational identification on student commitment, achievement and satisfaction in higher education. Studies in Higher Education, 41(12), 2232-2252.

Zhao, X., Lynch, J. G., \& Chen, Q. (2010). Reconsidering Baron and Kenny: Myths and truths about mediation analysis. Journal of Consumer Research, 37(2), 197-206. 